\title{
Geographical Speed Locking System
}

\author{
Rahul.B.M ${ }^{1}$, Vinay Kumar H S ${ }^{2}$, Prathap K S ${ }^{3}$, Gagandeep H C', \\ Dept. of Mechanical, SRSIT, \\ Bengaluru.
}

\begin{abstract}
This Paper describes geographical speed locking technique for the performance and enhancement of existing automobile industry. Nowadays people are driving very fast; accidents are occurring frequently, we lose our valuable lives by making small mistakes while driving (school zone, hills area, and highways). So, in order to avoid such kind of accidents and to alert the drivers and to control their vehicle speed, the highway department has placed the signboards. But sometimes it is possible to ignore those kinds of signboards and hence there are chances of accident. So, to notify the driver about the zones and the speed limit automatically, wireless technology can be used. The main objective is to design a Smart controller meant for vehicle's speed control, which can be run on an embedded system. Smart Control (SC) can be custom designed to fit into a vehicle. The project is composed of two separate units: zone status transmitter unit and receiver. Once the information is received from the zones, the vehicle's embedded unit automatically activates the vehicle, to reduce the speed according to the zone.
\end{abstract}

\section{INTRODUCTION}

Road facilities are a major concern in the developed world. Recent studies show that one third of the number of fatal or serious accidents are associated with excessive or inappropriate speed, as well as changes in the roadway (like the presence of road-work or unexpected obstacles).

Reduction of the number of accidents and mitigation of their consequences are a big concern for traffic authorities, the automotive industry and transport research groups. One important line of action consists in the use of advanced driver assistance systems (ADAS), which are acoustic, hectic or visual signals produced by the vehicle itself to communicate to the driver during the possibility of a collision.

These systems are somewhat available in commercial vehicles today, and future trends indicate that higher safety will be achieved by automatic driving controls and a growing number of sensors both on the road infrastructure and the vehicle itself. A prime example of driver assistance systems is cruise control (CC), which has the capability of maintaining a constant user preset speed and its evolution, the adaptive cruise control (ACC), which adds to $\mathrm{CC}$ the capability of keeping a safe distance from the preceding vehicle.

\section{LITERATURE REVIEW}

Decades ago there was a time when there were simple vehicles as the mode of transport. As the technology grew, the invention of the engines with different properties started and the competition began. Different automobile industries set up their standards with respect to different aspects. Speed played a major role among those various aspects. Most of the companies set up speed levels as one of their main features.
As competition grew, speed increased. When that speed reached some extreme level, it led to dangerous events like accidents etc.

When the rate of accidents increased, non-technically there came an idea of dropping speed at required zones.

Nowadays these speed breakers are also leading to various kinds of accidents. Later on, there came an idea of retractable humps, which detects the speed of the vehicle and then acts as a speed breaker. This technique aroused with many disadvantages. Hence the new technique of controlling the speed of the vehicle is needed.

So, for the future, here we come up with an idea of 'auto speed locking system' in the vehicles using geographical method and IR sensors.

In 2010, ERIC.J.E.MOLIN and her team from DUTCH UNIVERSITY researched on this topic and done a project on lock in \& its influence on vehicle to control speed.

In 2011, Dutch government tried this system and tested the speed locking technique.

In 2014, students from Angel college of engineering Tripura, India executed a project and explained the advance vehicle speed locking system by publishing an journal in IJAREEIE (International Journal of Advanced Research in Electrical, Electronics and Instrumentation Engineering)

In 2015, Mechanical engineering students from Kongu engineering college published a journal on automatic speed control of vehicle in restricted areas using RF \& GSM in IRJET (International Research journal of engineering \& technology).

In 2016, Electronics students of KL University executed GSM enabled vehicles speed limiting device and published that topic in IJST (Indian journal of Science \& Technology)

In 2016, Mechanical students from MIT, Moradabad published a journal of title speed control on DC motor using PWM in IJARCCE

(International Journal of Advanced Research in Computer and Communication Engineering).

In 2018, UG students of NIE college, Mysore executed and published a research journal an Intelligent vehicle speed controller in IRJET (International Research journal of engineering \& technology).

In 2018, UG students of SRMIST, executed a project on automatic speed control with wireless RF controller and 
published a journal in IJESRT (International Research journal of engineering science \& technology).

Referring all these techniques and upgrading them, here we came up with a project of controlling speed with respect to geographical regions and roads by using geographical positioning system (GPS).

\section{DESIGN AND COMPONENTS}

\section{A. DESIGN}

The main aim of our project is to control the over speeding of vehicles in school and college zones using wireless and automatic speed reduction gear changer implementation. Here we use the IR sensor and remote receiver and transmitter for detecting and controlling the speed of the vehicle. By this project we can control the vehicle speed through the radio frequency.

Fabrication of 4-wheel setup using dc motor and battery for the vehicle movement attached to the main shaft which consists of variable gear wheels to increase and decrease the rpm of the vehicle. The shaft is movable and fitted along the $\mathrm{dc}$ motor using small and big gears. The movement of the shaft operates through dc ejector which acts as the piston and helps the movement of the shaft to engage the opposite gears which is fixed.

The activation of gears is done automatically from the controller fitted in the vehicle called receiver and signal transmitter transmits the signal from the IR sensor to detect the vehicle in the predetermined area only. Two IR sensors are used, one IR is used for the incoming signal to the vehicle and transmitter transmits the wireless signal to the receiver of the vehicle which activates the ejector to change the high gear ratio to low gear ratio, to reduce the speed. Similarly, second IR sensor acts towards the outside vehicle movement and activates gears wirelessly from low speed to high speed.

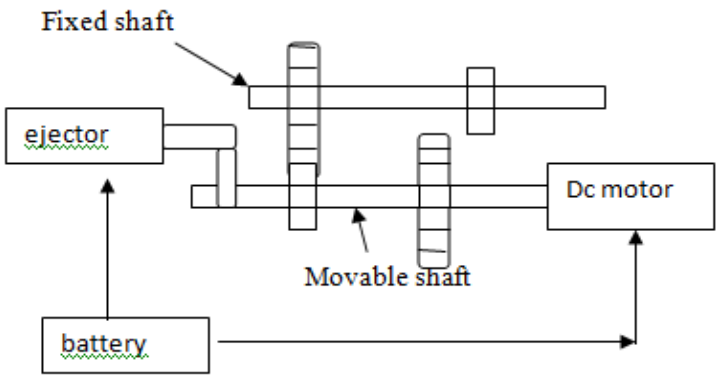

Figure: Breaking sytem model

\section{B. COMPONENTS}

\section{GEAR SHAFT:}

Gear shafts provide the rotation that allows one gear to engage with and turn another and contain gear teeth integrated into the shaft. A gear shaft with the gearing profiles at each end are called intersecting shaft gears.

\section{DC MOTOR}

DC motors take electrical power through direct current, and convert this energy into mechanical rotation. DC motors use magnetic fields that occur from the electrical currents generated, which powers the movement of a rotor fixed within the output shaft.

\section{IR SENSOR}

An infrared (IR) sensor is an electronic device that measures and detects infrared radiation in its surrounding environment. An infrared sensor emits and/or detects infrared radiation to sense its surroundings. The basic concept of an Infrared Sensor which is used as Obstacle detector is to transmit an infrared signal, this infrared signal bounces from the surface of an object and the signal is received at the infrared receiver.

\section{REMOTE CONTROLLER}

A transmitter is often a light emitting diode (LED) which is built into the pointing end of the remote-control handset. The infrared light pulses form a pattern unique to that button. The receiver in the device recognizes the pattern and causes the device to respond accordingly.

\section{ELECTRICAL FLOWCHART}

\section{A. TRANSMITTER}

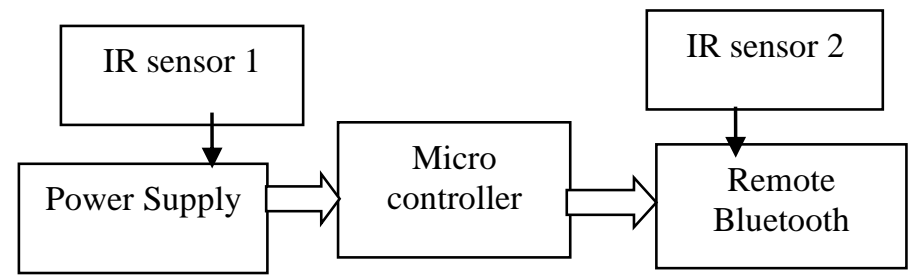

\section{B. RECIEVER}

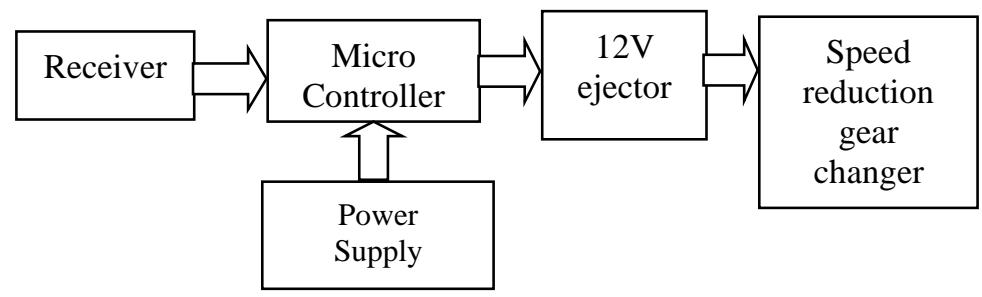

\section{ADVANTAGES AND APPLICATIONS}

1) Speed control through wireless technique.

2) Speed control at humps.

3) Speed controls when any obstacle found

4) U curves safety indications.

5) Low power transmitter is enough for operation.

6) Lot of accidents can be avoided.

7) Suitable for all kinds of vehicle safety system.

8) Less man power is required

9) Steep edges are detected.

10) Driver alertness will be more.

11) High, low beam of headlights are controlled automatically. 
12) Controlling the horn of the vehicles across schools, hospitals etc.

13) Because of using solar it will be cost effective.

\section{PROPOSED RESULT}

The proposed result for this topic is to prepare a model which will show the experimental view of this project covering the theoretical as well as practical areas related to this project. This model will also show the practical implementation of the device. We are trying to work with the all-pros and cons related to this project. Hopefully, we will come with a model which will show the experimental view of Smart Display and Control Device through which the idea of automated speed control concept, to prevent the accident and control traffic, would be more clearly understood. We are actually presenting the layout of the project on which we will be working. Basically, it consists of two sections: zone status transmitter according to the zone - it waits for few seconds, and, control unit and receiver unit (speed display unit).

Once the information is received from the zones, the vehicle's embedded unit will automatically alert the driver to reduce the vehicle's speed. Smart Control unit automatically reduces the speed.

\section{CONCLUSION}

Here by we conclude that this project is very easy to implement on current system, low cost and durable, ensures maximum safety to passengers and public, the driver gets all information about the road without distracting him from driving, driver gets all information even in bad weather conditions, low power consumption. This project is further enhanced by automatic speed control when the vehicles get any hazard signal from outside environment.

\section{REFERENCES}

[1] Shamsudin, T.M.W. Salami, M.J.E. Martono, W," RFID Based Intelligent breaking System," presented at the Annual RFID Eurasia Conference and Exhibition, Istanbul Sep 5,6-2007 J. Clerk Maxwell, A Treatise on Electricity and Magnetism, 3rd ed., vol. 2. Oxford: Clarendon, 1892, pp.68-73.

[2] Umar Farooq, Muhammad Amar, K. M, Hasan, Muhammad Usman Asad and Asim lqbal, "Automatic speed control system, International Journal of Computer Theory and Engineering, vol. 2, no. 4, pp. 1793 8201, August, 2010.

[3] Elisabeth llie-Zudor, Zsolt Kemény, Péter Egri, László Monostori, "The RFID Technology and Its Current Applications," in Proc. Of the Modern Information Technology in the Innovation Processes of Industrial Enterprises, 2006, pp.29-36.

[4] In 2015, Mechanical engineering students from Kongu engineering college published a journal on automatic speed control of vehicle in restricted areas using RF \& GSM in IRJET (International Research journal of engineering \& technology).

[5] In 2016, Electronics students of KL University executed GSM enabled vehicles speed limiting device and published that topic in IJST (Indian journal of Science \& Technology)

[6] In 2016, Mechanical students from MIT, Moradabad published a journal of title speed control on DC motor using PWM in IJARCCE

(International Journal of Advanced Research in Computer and Communication Engineering) 